Int. J. Dev. Biol. 55: 5-10 (2011)

doi: $10.1387 / \mathrm{ijdb} .1030941 \mathrm{~s}$

\title{
Stomatal development in Arabidopsis and grasses: differences and commonalities
}

\author{
LAURA SERNA* \\ Facultad de Ciencias del Medio Ambiente, Universidad de Castilla-La Mancha, Toledo, Spain
}

\begin{abstract}
Stomata, found on the epidermis of all terrestrial plants, consist of two specialized cells called guard cells, which surround a tiny pore. Major advances have been made in our understanding of the genetic control of stomatal development in Arabidopsis and grasses. In Arabidopsis, three basic-helix-loop-helix (bHLH) genes control the successive steps that lead to stomatal formation. SPEECHLESS (SPCH) drives the cell division that initiates the stomatal cell lineage, MUTE induces the formation of the immediate stomatal precursor cell, and FAMA causes the stomatal precursor cell to divide into the two guard cells. Recent results demonstrate that these genes share functions with their grass homologs, and that MUTE is expressed later in development than its grass counterparts. Other differences in stomatal development between these two plant groups are exemplified by the PANGLOSS1 (PAN1) gene of maize. PAN1, which encodes a leucine-rich repeat receptor-like kinase with an inactive kinase domain, promotes polarization of the subsidiary mother cell and orients its cell division plane. Because such events do not exist in Arabidopsis, it is likely that the PAN1-like genes of Arabidopsis and PAN1 are paralogs. Together, these results indicate that distinctions in the regulation of gene expression and protein function are both responsible for the divergence of stomatal development between Arabidopsis and grasses.
\end{abstract}

KEY WORDS: Arabidopsis, bHLH, grasses, PAN1, stomata

\section{Introduction}

The evolution of a hydrophobic cuticle that covers all aboveground plant surfaces and that is interrupted by stomatal pores allowed plants to survive on land (Edwards et al., 1998). Stomatal pores, which seem to have arisen once during evolution, are present in the sporophyte generation of all land plants except for the liverworts (Raven, 2002). They are surrounded by two guard cells that swell following the influx of water from adjacent epidermal cells (Taiz and Zeiger, 2006). When the guard cells swell, the pore opens. Guard cells also contract upon water loss, which induces stomatal closure. The main function of stomata in vascular plants is to facilitate the capture of atmospheric $\mathrm{CO}_{2}$ for photosynthesis, while keeping water loss to a minimum (Taiz and Zeiger, 2006).

It has been proposed that the stomata of vascular plants have never been replaced by other structures because they have been essential for adaptation to the terrestrial environment throughout land plant evolution. However, both the structure and the distribu- tion of guard cells vary among plant groups. Kidney-shaped guard cells are characteristic of most dicots and non-graminaceous monocots, and dumbbell-shaped guard cells are typical in grasses and most other monocots (Weyers and Meidner, 1990). In grasses, leaves exhibit parallel venation, and stomata are arranged in linear files that make contact with non-stomatal-forming files. In contrast, dicots have reticulate venation, and stomata are scattered across the leaf surface (Hickey, 1979; Judd et al., 1999; Fig. 1). These differences in stomatal patterns between grasses and dicots are a consequence of the developmental processes that give rise to stomata.

The cellular bases of stomatal development have been explored in numerous dicot species, with Arabidopsis thaliana being the best-studied system. Stomatal development in this model

Abbreviations used in this paper: BASL, BREAKING OF ASYMMETRY IN THE STOMATAL LINEAGE; bHLH, basic helix-loop-helix; EPF, EPIDERMAL PATTERNING FACTOR; PAN1, PANGLOSS1; SCREAM, SCRM; SPCH, SPEECHLESS, TMM, TOO MANY MOUTHS.

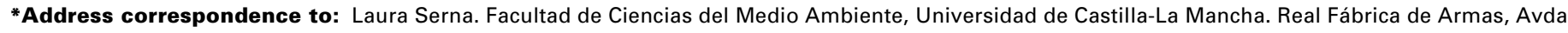
Carlos III, s/n, 45071 Toledo, Spain. Fax: +34-925-268840. e-mail: laura.serna@uclm.es
} 
A

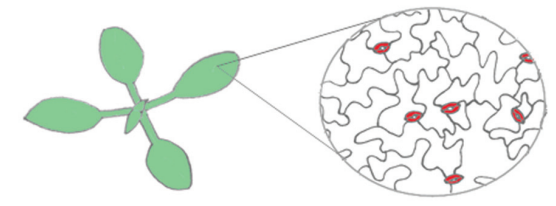

B

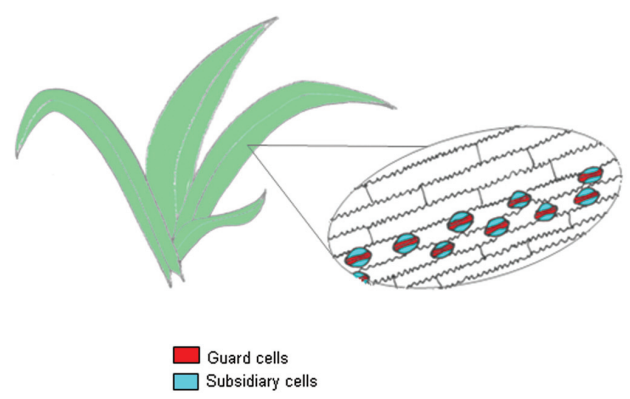

Fig. 1. The epidermis of Arabidopsis and rice leaves. (A) Arabidopsis. Cells are randomly arranged, with stomata (paired guard cells) scattered across the surface. (B) Rice. Cells are arranged in linear files, with some files bearing stomata flanked by two subsidiary cells.

plant starts with the division of an epidermal cell termed the meristemoid mother cell (Bergmann and Sack, 2007; Serna, 2007; Fig. 2A). This asymmetric cell division produces a small, triangular meristemoid cell and a larger cell. Meristemoids can divide asymmetrically in an inward spiral up to three times, always producing a larger cell and a smaller meristemoid that maintains its stem cell character. After these asymmetric cell divisions, the meristemoid loses its stem cell activity and acquires a subangular or rounded shape, which gives rise to the guard mother cell. The guard mother cell divides symmetrically to produce a pair of guard cells, which do not divide further. Although stomatal development occurs in a basipetal manner, with stomata maturing towards the leaf apex, new meristemoids arise among mature stomata, allowing intercalary growth.

In grasses, stomatal development starts with an asymmetric division, which yields the guard mother cell (Stebbins and Shah, 1960; Fig. 2B). Before it produces the paired guard cells, the lateral neighbors of the guard mother cell, termed subsidiary mother cells, divide asymmetrically to produce the two subsidiary cells. The guard mother cell then undergoes a symmetric cell division to generate paired guard cells, which are flanked by the subsidiary cells. In contrast to what is observed in dicots, stomatal development in grasses initiates at the leaf base, while cells expand and mature only near the apex.

During the last few years, an increasing number of genes regulating Arabidopsis stomatal development have been discovered (Peterson et al., 2010). Many of them function in a signalling cascade, which is initiated at the cell surface through the activation of the membrane receptors TOO MANY MOUTHS (TMM) and/or ERECTA family members by members of the EPIDERMAL PATTERNING FACTOR family (EPF1, EPF2, STOMAGEN/ EPFL9, CHALLAH/EPFL6), and/or a substrate processed proteolytically by the subtilase STOMATAL DENSITY AND DISTRIBUTION1 and transduced through cytoplasmic MAP kinases (YODA, MKK4/ MKK5, and MPK3/MPK6) towards the nucleus. These components negatively regulate the development of su- pernumerary stomata and enhance spacing among stomata. In the nucleus, these MAP kinases regulate the activity of the basic helix-loop-helix (bHLH) proteins SPEECHLESS (SPCH), MUTE, and FAMA, which act in concert with the bHLH-Leu zipper proteins SCREAM1 and SCREAM2 promoting stomatal development. The recent availability of genome sequences from grasses like rice (Oryza sativa) and maize (Zea mays) has permitted the analysis of genes that are homologs of Arabidopsis genes implicated in stomatal development (Liu et al., 2009), as well as the analysis of genes that most probably function exclusively in grasses (Cartwright et al., 2009). This review mainly focuses on the functions of SPCH, MUTE, FAMA and their homologs in grasses, highlighting the differences and commonalities of stomatal development in these two plant groups. The role of PANGLOSS1 (PAN1) gene of maize, which encodes a leucinerich repeat receptor-like kinase with an inactive kinase domain (Cartwright et al., 2009), is also highlighted.

\section{Orthologs and paralogs of SPCH-like genes}

In Arabidopsis, stomatal development starts with an asymmetric cell division. Mutations in the Arabidopsis gene $\mathrm{SPCH}$ that abolish its expression prevent the initiation of stomatal development and give rise to an epidermis consisting of only jigsaw puzzle-shaped pavement cells (MacAlister et al., 2007; Pillitteri et al., 2007). Thus, SPCH, which encodes a bHLH protein, is thought to drive the first asymmetric cell division that initiates stomatal development (MacAlister et al., 2007; Pillitteri et al., 2007). In support of this role, the overexpression of $\mathrm{SPCH}$ results in numerous extra cell divisions (MacAlister et al., 2007; Pillitteri et al., 2007). In addition to regulating the first asymmetric cell division that accounts for stomatal development, SPCH apparently maintains the stem cell activity of meristemoids (MacAlister et al., 2007): the missense mutation spch-2, which affects the carboxy terminus of the protein, reduces the number of cells entering the stomatal pathway and appears to trigger premature stomatal formation in the pedicel epidermis. SPCH promoter activity is observed in undifferentiated cells and persists in stomatal lineage cells, including guard cells (MacAlister et al., 2007; Pillitteri et al., 2007). However, the encoded protein is restricted to the early stages of the stomatal lineage, suggesting that the $\mathrm{SPCH}$ protein might be post-transcriptionally downregulated (MacAlister et al., 2007). These expression patterns are consistent with a role for $S P C H$ in determining the entrance into the stomatal lineage and perhaps a later role in maintaining the stem cell activity of meristemoids.

In contrast to the single SPCHgene of Arabidopsis, poplar and Ricinus, Liu et al. found two SPCH-like genes in both $O$. sativa (OsSPCH1 and OsSPCH2) and Z. mays ( $\mathrm{ZmSPCH} 1$ and $\mathrm{ZmSPCH} 2$ ). Like SPCH, OsSPCH2, ZmSPCH1 and $\mathrm{ZmSPCH} 2$ contain an $\mathrm{N}$-terminal acidic region and, also like $\mathrm{SPCH}$, the four grass homologs have a conserved mitogen-activated protein kinase (MAPK) target domain (Liu et al., 2009). The MAPK target domain of SPCH is phosphorylated by MAPKs (Lampard et al., 2008). Interestingly, the SPCH phosphorylation sites are conserved in the grass homologs (Lampard et al., 2008; Liu et al., 2009), suggesting that the SPCH function is also conserved in grasses. Certainly, in the case of $\mathrm{OsSPCH}$, this is supported by the observation that overexpression of $\mathrm{SPCH}$ under the control of 
the Cauliflower Mosaic Virus $35 S$ (35S) promoter leads to a phenotype identical to that induced by OsSPCH2 overexpression, which consists of ectopic divisions in pavement cells (MacAlister et al., 2007; Liu et al., 2009). Furthermore, rice plants homozygous for the osspch2-1 insertion, like Arabidopsis plants harboring the weak spch-2 allele, have a reduced number of stomata (MacAlister et al., 2007; Liu et al., 2009). However, in contrast to the spch-2 mutant, osspch2-1 plants occasionally also develop stomatal patterning defects, and expression of $\mathrm{OsSPCH} 2$ under the SPCH promoter fails to rescue the Arabidopsis spch phenotype (Liu et al., 2009). Therefore, although OsSPCH2 and $S P C H$ appear to share some functions, their regulatory roles are not identical (Liu et al., 2009). OsSPCH2 controls patterning and it presumably has no role in the maintenance of meristemoid stem fate, given that rice meristemoids develop into guard mother cells without undergoing repeated rounds of asymmetric cell division. Remarkably, although OsSPCH2 seems to control stomatal development, its expression has not been detected in leaves (Liu et al., 2009). Overexpression of OsSPCH1 by the $35 S$ promoter does not confer an apparent phenotype (Liu et al., 2009), suggesting that the OsSPCH1 function might have diverged from that of both $\mathrm{OsSPCH} 2$ and $S P C H$. In support of this view, OsSPCH1 lacks the $\mathrm{N}$-terminal acidic region that characterizes $\mathrm{SPCH}$ proteins (Liu et al., 2009). In addition, the OsSPCH1 transcript was not detected in leaves (Liu et al., 2009). Mutation analysis of the OsSPCH1 gene and cross-species tests will confirm (or annul) this apparent divergence.
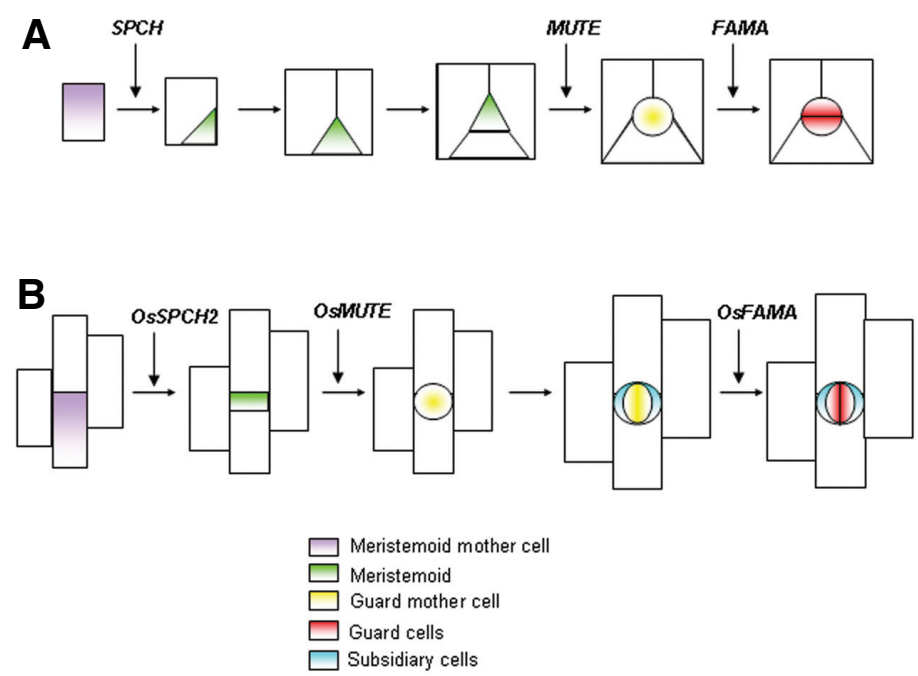

Fig. 2. Stomatal development and $\boldsymbol{b H} \boldsymbol{H} \boldsymbol{H}$ genes. (A) Arabidopsis. SPEECHLESS (SPCH) initiates stomatal development by inducing the first asymmetric division, which gives rise to the first meristemoid. Two or three divisions after SPCH, MUTE represses the stem cell character of meristemoids and induces guard mother cell formation. FAMA then drives the symmetric division that gives rise to the two guard cells. (B) Rice. OsSPCH2 regulates the first asymmetric cell division in the stomatal lineage, which produces a meristemoid. Immediately afterwards, OsMUTE represses the stem cell character of the meristemoid and triggers guard mother cell differentiation. Consequently, meristemoids do not manifest stem cell properties. The lateral neighbors of the guard mother cell then divide asymmetrically to form stomatal subsidiary cells. Finally, OsFAMA causes the guard mother cell to divide, producing two guard cells. Adapted from (Serna, 2007; Liu et al., 2009).
In summary, these findings strongly suggest that Arabidopsis $S P C H$ and rice $\mathrm{OsSPCH} 2$ share some functions. Interestingly, OsSPCH1, which most probably originated as an OsSPCH2 gene duplication, seems to have diverged from OsSPCH2 and lost its function, and perhaps it acquired a new one. Certainly, when a gene duplicates, one copy generally retains the ancestral function, whereas the other copy is free to accumulate mutations (Ohno, 1970). Data on the role of SPCH-like genes in maize will reveal valuable information to extend the discussion on the molecular evolution of stomatal development to grasses.

\section{MUTE-like genes may act earlier in grasses than in Arabidopsis}

After a few cell divisions, meristemoids lose their stem cell identity and become guard mother cells, which then produce paired guard cells. MUTE plays an essential role in this transition by repressing the stem cell activity of meristemoids; the loss-offunction mute-1 mutant does not develop stomata but forms meristemoids that abort after excessive asymmetric cell divisions (MacAlister et al., 2007; Pillitteri et al., 2007). The MUTE promoter is active in a subset of meristemoids, with residual activity in guard mother cells and immature stomata, whereas MUTE protein is restricted solely to a subset of meristemoids (MacAlister et al., 2007; Pillitteri et al., 2007). It is therefore probable that, in this subset of meristemoids, MUTE represses stem cell activity and induces guard mother cell formation. The fact that MUTE overexpression converts all epidermal cells into stomata is consistent with the function of this gene (MacAlister et al., 2007; Pillitteri et al., 2007).

Liu et al. found that, as in Arabidopsis, MUTE-like genes are present in grasses as single-copy genes. In addition, OsMUTE cDNA driven by the MUTE promoter partially rescues the mute-1 phenotype by inducing the development of guard cells at the edges of leaves, while meristemoids remain arrested in the central regions of leaves (Liu et al., 2009). Like OsMUTE, ZmMUTE expressed under the control of the MUTE promoter also complements the Arabidopsis mute-1 mutant (Liu et al., 2009). These lines of evidence suggest that the function of MUTE-like genes is conserved in grasses and Arabidopsis. Interestingly, the stomatal phenotype of Arabidopsis overexpressing either ZmMUTE or OSMUTE is similar to that caused by MUTE overexpression (at least when expression is at very high levels), in that all of the epidermal cells in cotyledons and leaves are guard cells (MacAlister et al., 2007; Pillitteri et al., 2007; Liu et al., 2009). This finding also supports the designation of these genes as orthologs.

However, it remains undetermined whether MUTE-like genes abolish the stem cell character of meristemoids in grasses, and if so, how do they do this? Interestingly, grass meristemoids develop directly into guard mother cells without undergoing repeated rounds of asymmetric cell division. Grass MUTE-like genes may be expressed earlier in development than their Arabidopsis ortholog, that is, before the stem cell character of the meristemoids is manifested. Certainly, Liu et al. demonstrated that both OSMUTE and ZmMUTE are expressed when cell files are forming. Also consistent with this suggestion, OsMUTE::GUS expression in Arabidopsis is not restricted to a subset of meristemoids, but instead resembles the broad early expression pattern of the SPCH::GUS construct (MacAlister et al., 2007; 
Pillitteri et al., 2007; Liu et al., 2009). This result suggests that premature expression of OSMUTE (and ZmMUTE) may force guard mother cell formation after the first asymmetric cell division, preventing the stem cell activity of rice (and maize) meristemoids from persisting. If this is true, loss-of-function mutants of OSMUTE or ZmMUTE might be expected to have a phenotype similar to that of the loss-of-function mute-1 mutant. Also, an obvious and testable corollary is that MUTE expressed under the control of the OSMUTE (or ZmMUTE) promoter in Arabidopsis should force meristemoids to develop directly into guard mother cells without undergoing repeated rounds of asymmetric cell division.

In contrast to both SPCH and FAMA, MUTE lacks both an Nterminal extension and a MAPK target domain. However, maize and rice MUTE orthologs exhibit multiple potential MAPK phosphorylation sites (Liu et al., 2009). It will be interesting to establish if there is any relationship between the presence of these MAPK phosphorylation sites in both OsMUTE and ZmMUTE, with respect to differences between the MUTE and OSMUTE (or ZmMUTE) expression patterns. Anyway, modifications in transcriptional regulation comprise an important component for the evolution of organismal phenotypes (Wray et al., 2003; Wray, 2003).

\section{The role of $F A M A-l i k e$ genes is conserved in rice}

In all plant species examined, the guard mother cell undergoes a symmetrical cell division to produce the two guard cells that form the stoma. In Arabidopsis, this transition from the guard mother cell to two fully differentiated guard cells is controlled by the FAMA

\section{A}

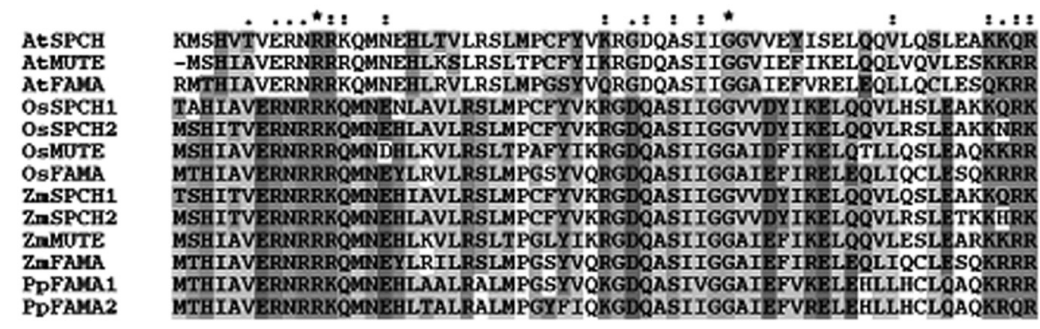

B

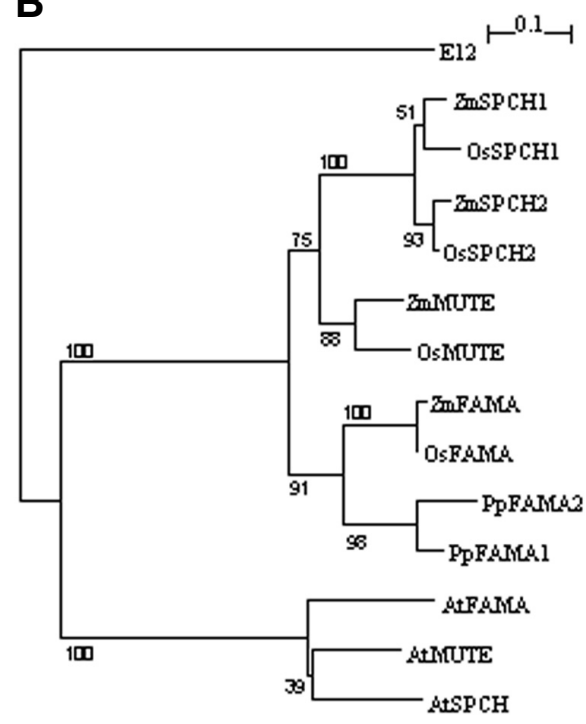

Fig. 3. Comparison and phylogeny of bHLH proteins regulating stomatal development. (A) Sequence comparisons among the bHLH domains. Asterisks show identical residues, colons indicate conservative changes, and periods show semiconservative changes. (B) Phylogeny of the bHLH proteins that regulate stomatal development. E12 serves as an outgroup. The bHLH domains were used to calculate the neighbour-joining phylogenetic tree. Branch lengths are proportional to sequence distance. Bootstrap values are based on 1,000 replicates. ClustalX2 software was used. gene, which encodes a member of the bHLH family of transcripion factors (Ohashi-Ito and Bergmann, 2006). Plants homozy(1) exhibit clusters of guard mother cells or immare guard cells instead of fully differentiated stomata (Ohashi-Ito (Ohashi-Ito and Bergmann hich prevents tumor formation, and triggers the formation paired guard cells. The expression of FAMA is restricted to guard mother cells and differentiating guard cells, and the FAMA protein ocalizes to the nuclei of these cells (Ohashi-Ito and Bergmann, 06).

Both maize and rice encode a single FAMA homolog, which are very similar (more than $90 \%$ ) to the Arabidopsis FAMA sequence et al., 2009). Like FAMA, these protein homologs contain an acidic domain (Liu et al., 2009) that is required to tivate transcription (Ohashi-Ito and Bergmann, 2006). Liu et al. (osfama-1), which also lack OsFAMA transtead of fully differentiated stomata. In contrast to the fama-1 mutation, the osfama-1 allele does not cause numerous tumorlike cells to form in stomatal cell rows (Liu et al., 2009). Thus, expression of OsFAMA in Arabidopsis under the control FAMA promoter partially rescues the fama-1 phenotype, stomata that mature but that are arranged in tumors. Two explanations may account for these observations: 1) OsFAMA may have lost (or FAMA may have gained) part of its function in restricting cell division, and 2) the FAMA and OsFAMA functions are fully conserved, and rice guard mother cells, but not Arabidopsis guard mother cells, have cell cycle control features that prevent cell divisions upstream of OsFAMA.

Overexpression of OsFAMA under the control of the $35 S$ promoter, like that of $F A M A$, induces the production of unpaired guard cells (Liu et al., 2009). Guard mother cells may develop into guard cells without undergoing a symmetrical division (Ohashi-Ito and Bergmann, 2006). Thus, the levels of both FAMA and OsFAMA may be essential for regulating cell division, with high levels repressing cell division and forcing guard mother cells to directly differentiate into guard cells (Ohashi-Ito and Bergmann, 2006).

Characterization of the FAMA-like gene function in rice suggests that the ability of $F A M A$-like genes to drive the transition from guard mother cells to fully differentiated guard cells is conserved, at least in Arabidopsis and rice. More data on the role of FAMAlike genes in maize and in other plant species are required to further understand the function of FAMAlike genes in grasses.

\section{PAN1 and subsidiary cell formation in maize}

In grasses, before guard mother cells produce paired guard cells, subsidiary mother cells polarize towards 
the guard mother cell (Cho and Wick, 1990; Gallagher and Smith, 2000; Panteris et al., 2006). This polarization is marked by the migration of the nucleus towards the guard mother cell and the formation of dense patches of cortical F-actin at the guard mother cell contact site. Mutations in two maize genes, PAN1 and PAN2, cause defects in these two processes (Cartwright et al., 2009). They also cause aberrant subsidiary mother cell divisions (Cartwright et al., 2009). Thus, both PAN1 and PAN2 promote the polarization of the asymmetric subsidiary mother cell division and orient its cell division plane (Cartwright et al., 2009). PAN1, which encodes a member of the leucine-rich repeat receptor-like kinase family, localizes within subsidiary mother cells to sites where these cells contact guard mother cells (Cartwright et al., 2009). Analysis of PAN1-dependent protein phosphorylation revealed that PAN1 has an inactive kinase domain (Cartwright et al., 2009). Consistent with these data, PAN1 lacks several amino acid residues that are critical for kinase activity (Hanks et al., 1995; Cartwright et al., 2009).

In Arabidopsis, the TMM gene also directs asymmetric cell division in stomatal development (Nadeau and Sack, 2002). TMM contains leucine-rich repeat and transmembrane domains, but it does not have a kinase domain (Nadeau and Sack, 2002). However, in contrast to PAN1, TMM does not promote the polarization of these asymmetric cell divisions, nor is it asymmetrically localized (Nadeau and Sack, 2002). Like PAN1 (and PAN2), the Arabidopsis BREAKING OF ASYMMETRY IN THE STOMATAL LINEAGE (BASL) gene controls both the polarization of stomatal lineage cells and orients their asymmetric cell divisions (Dong et al., 2009). Mutations in BASL disrupt the physical asymmetry of stomatal linage division and cause the production of more stomata (Dong et al., 2009). BASL, which is expressed in stomatal lineage cells, encodes a novel protein for which homologs are found only in plants (Dong et al., 2009). Also like PAN1, BASL exhibits a polar localization at the cell periphery in asymmetrically dividing cells (Cartwright et al., 2009; Dong et al., 2009). But unlike PAN1, BASL forms a crescent distal to the nucleus and it also accumulates in the nucleus (Cartwright et al., 2009; Dong et al., 2009).

TMM functions in a well-characterized signal transduction pathway (Bergmann and Sack, 2007). However, the up- and downstream components of the pathways in which PAN1 and $B A S L$ operate are incomplete. The absence of PAN1 patches and the reduction of PAN1 levels in the pan2 mutant suggest that $P A N 1$ functions downstream of PAN2, whose molecular nature remains unknown (Cartwright et al., 2009). Future goals include unravelling the components of the pathways in which PAN1 and $B A S L$ function, and identifying the PAN2 gene product. Studies on the role of PAN1-like genes in Arabidopsis and in other grasses, and of TMM- and BASL-like genes in grasses, may reveal valuable information on the roles of these genes in the evolutionary context. Given that the asymmetric cell divisions that produce the subsidiary cells in grasses do not exist in Arabidopsis, it is likely that the PAN1 and PAN1-like genes of Arabidopsis are paralogs.

\section{Concluding remarks}

Classification of plant bHLH proteins has allowed inferring that members of the same subfamily usually play redundant roles
(Pires and Dolan, 2010). Strikingly, Pires and Dolan (2010) found that members of subfamily la proteins, which include $\mathrm{SPCH}$, MUTE, FAMA, OsMUTE, OsFAMA and OsSPCH2, play nonoverlapping roles. An attractive hypothesis considers that the $b H L H$ genes encoding these proteins might have derived from a single $b H L H$ gene in the ancestor of land plants, which would trigger the first asymmetric cell division and immediately guard cells formation. Interestingly, the moss Physcomitrella patens does not have SPCH-or MUTE-like genes, but has two FAMA-like genes (Peterson et al., 2010). Consistently, stomata in moss develop through a single asymmetric cell division to produce the guard mother cell, which then divides to produce the paired guard cells (Payne, 1979). Then, it is likely that MUTE- and SPCH-like genes arose from duplications and divergences of FAMA-like genes, which allowed an increase in the complexity of stomatal development. In agreement with this view, the bHLH proteins of Arabidopsis and grasses fall into different evolutionary lineages (Fig. 3). Interestingly, FAMA is less similar to ZmFAMA and OsFAMA than is PpFAMA1 and PpFAMA2 (Fig. 3), which supports that stomatal development of Physcomitrella patens is more similar to that of grasses than that of Arabidopsis.

Knowledge of the functions of SPCH, MUTE and FAMA in Arabidopsis has facilitated understanding the roles of their orthologs in grasses (Table 1). Differences in the expression of MUTE-like genes appear to have contributed to the divergent patterns of stomatal development between Arabidopsis and grasses. The presence of homologs of the Arabidopsis signalling genes (for example, YODA and TMM) in grasses (Peterson et al., 2010) suggests that a similar signalling cascade guides stomatal development in both groups. Similarly, the presence in rice of homologs of the Arabidopsis bHLHs ICE1/SCREAM (SCRM) and SCRM2, which seem to control stomatal development through their physical interaction with SPCH, MUTE, and FAMA (Kanaoka et al., 2008; Liu et al., 2009), suggests that similar multimeric complexes trigger stomatal development in the two plant groups. In contrast, the development of trichomes in Arabidopsis and grasses most likely depends on different transcriptional regula-

TABLE 1

\section{bHLH GENES REGULATING STOMATAL DEVELOPMENT IN ARABIDOPSIS AND GRASSES}

\begin{tabular}{|c|c|c|}
\hline Gene name & Function & Reference \\
\hline AtSPCH & $\begin{array}{l}\text { Drives the first asymmetric cell division. Maintains the } \\
\text { stem cell activity of Ms }\end{array}$ & $\begin{array}{l}\text { MacAlister et al., 2007; } \\
\text { Pillitteri et al., } 2007\end{array}$ \\
\hline $\mathrm{OsSPCH} 1$ & $\begin{array}{l}\text { Plays no role in stomatal development. Its function } \\
\text { might have diverged from that of both } \mathrm{OsSPCH} 2 \text { and } \\
\text { AtSPCH }\end{array}$ & Liu et al., 2009 \\
\hline $\mathrm{OsSPCH} 2$ & $\begin{array}{l}\text { Drives the first asymmetric cell division. Controls } \\
\text { stomatal patterning }\end{array}$ & Liu et al., 2009 \\
\hline $\mathrm{Zm} \mathrm{SPCH1}$ & Might play a similar role to $\mathrm{OsSPCH} 1$ & Liu et al., 2009 \\
\hline $\mathrm{Zm} \mathrm{SPCH} 2$ & Might play a similar role to $\mathrm{OsSPCH} 2$ & Liu et al., 2009 \\
\hline AtMUTE & $\begin{array}{l}\text { Represses stem cell fate of Ms and promotes GMC } \\
\text { formation }\end{array}$ & $\begin{array}{l}\text { MacAlister et al., 2007; } \\
\text { Pillitteri et al., } 2007\end{array}$ \\
\hline OsMUTE & $\begin{array}{l}\text { Forces GMC formation after the first asymmetric cell } \\
\text { division }\end{array}$ & Liu et al., 2009 \\
\hline ZmMUTE & $\begin{array}{l}\text { Forces GMC formation after the first asymmetric cell } \\
\text { division }\end{array}$ & Liu et al., 2009 \\
\hline AtFAMA & $\begin{array}{l}\text { Stops the proliferation of GMCs and drives the } \\
\text { transition from the GMC to the GCs }\end{array}$ & $\begin{array}{l}\text { Ohashi-lto and } \\
\text { Bergmann, } 2006\end{array}$ \\
\hline OsFAMA & Drives the transition from the $\mathrm{GMC}$ to the $\mathrm{GCs}$ & Liu et al., 2009 \\
\hline$Z m F A M A$ & Might play a similar role to OSFAMA & Liu et al., 2009 \\
\hline
\end{tabular}


tory networks (Serna and Martin, 2006).

The acquisition of the PAN1 function in grasses (or its hypothetical loss in Arabidopsis) may also have contributed to divergences in stomatal development between Arabidopsis and grasses. Determining whether the commonalities and differences relative to stomatal development extend beyond these plant groups is essential for an in-depth understanding of the molecular evolution of stomatal development. Some interesting models of the roles that these genes may have in plants other than Arabidopsis and grasses have been proposed (Peterson et al., 2010). Future work will determine if these models reflect reality.

\section{Acknowledgements}

This work is supported by a Grant (BIO2008-02149) from the Spanish Ministry of Science and Innovation and partially by a Grant (PCI08-00411136) from the Autonomic Government of Castilla-La Mancha. I thank $D$. $C$. Bergmann for generously providing the grasses bHLH sequences.

\section{References}

BERGMANN, D.C. and SACK, F.D. (2007). Stomatal development. Annu Rev Plant Biol 58: 163-181.

CARTWRIGHT, H.N., HUMPHRIES, J.A. and SMITH, L.G. (2009). PAN1: A receptor-like protein that promotes polarization of an asymmetric division in maize. Science 323: 649-651.

CHO, S.O. and WICK, S.M. (1990). Distribution and function of actin in the developing stomatal complex of winter rye (Secale cereale cv. Puma). Protoplasma 157: 154-164.

DONG, J., MACALISTER, C.A. and BERGMANN, D.C. (2009).nBASL controls asymmetric cell division in Arabidopsis. Cell 137: 1320-1330.

EDWARDS, D., KERP, H. and HASS, H. (1998). Stomata in early land plants: an anatomical and ecophysiological approach. J Exp Bot 49: 255-278.

GALLAGHER, K. and SMITH, L.G. (2000). Roles for polarity and nuclear determinants in specifying daughter cell fates after an asymmetric cell division in the maize leaf. Curr Biol 10: 1229-1232.

HANKS, S.K. and HUNTER, T. (1995). Protein kinases 6. The eukaryotic protein kinase superfamily: kinase (catalytic) domain structure and classification. FASEB J 9: 576-596.

HICKEY, L. (1979). A revised classification of the architecture of dicotyledonous leaves. In Anatomy of the dicotyledons (Eds. C.R. Metcalfe and L. Chalk). Second Edition, Vol. 1. Clarendon Press, Oxford, pp. 25-39.

JUDD, W.W., CAMPELL, C.S., KELLOGG, E.A. and STEVENS, P.F. (Ed.) (1999). Plant systematics: A phylogenetic approach. Sinauer Associates, Sunderland, MA.

KANAOKA, M.M., PILLITTERI, L.J., FUJII, H., YOSHIDA, Y., BOGENSCHUTZ, N.L., TAKABAYASHI, J., ZHU, J.-K. and TORII, K.U. (2008). SCREAM/ICE1 and SCREAM2 specify three cell-state transitional steps leading to Arabidopsis stomatal differentiation. Plant Cell 20: 1775-1785.

LAMPARD, G.R., MACALISTER, C.A. and BERGMANN, D.C. (2008). Arabidopsis stomatal initiation is controlled by MAPK-mediated regulation of the bHLH SPEECHLESS. Science 322: 1113-1116.

LIU, T., OHASHI-ITO, K. and BERGMANN, D.C. (2009). Orthologues of Arabidopsis Thaliana stomatal bHLH genes and regulation of stomatal development in grasses. Development 136: 2265-2276.

MACALISTER, C.A. et al. (2007). Transcription factor control of asymmetric cell divisions that establish the stomatal lineage. Nature 445: 537-540.

NADEAU, J.A. and SACK, F.D. (2002). Control of stomatal distribution on the Arabidopsis leaf surface. Science 296: 1697-1700.

OHASHI-ITO, K. and BERGMANN, D.C. (2006). Arabidopsis FAMA controls the final proliferation/differentiation switch during stomatal development. Plant Cell 18: 2493-2505.

OHNO, S. (Ed.) (1970). Evolution by gene duplication. Springer-Verlag.

PANTERIS, E., APOSTOLAKOS, P. and GALATIS, B. (2006). Cytoskeletal asymmetry in Zea mays subsidiary cell mother cells: a monopolar prophase microtubule half-spindle anchors the nucleus to its polar position. Cell Motil Cytoskeleton 63: 696-709.

PAYNE, W.W. (1979). Stomatal patterns in embryophytes - Their evolution, ontogeny and interpretation. Taxon 28: 117-132.

PETERSON, K.M., RYCHEL, A.L. and TORII, K.U. (2010). Out of the mouths of plants: the molecular basis of the evolution and diversity of stomatal development. Plant Cell 22: 296-306.

PILLITTERI, L.J., SLOAN, D.B., BOGENSCHUTZ, N.L. and TORII, K.U. (2007). Termination of asymmetric cell division and differentiation of stomata. Nature 445: 501-505.

PIRES, N. and DOLAN, L. (2010). Origin and diversification of basic-helix-loophelix proteins in plants. Mol Biol Evol 27: 862-874.

RAVEN, J.A. (2002). Selection pressures on stomatal evolution. New Phytol 153: 371-386.

SERNA, L. and MARTIN, C. (2006). Trichomes: different regulatory networks lead to convergent structures. Trends Plant Sci 11: 276-280.

SERNA, L. (2007). bHLH proteins know when to make a stoma. Trends Plant Sci 12: 483-485.

STEBBINS, G.L. and SHAH, S.S. (1960). Developmental studies of cell differentiation in the epidermis of monocotyledons. I. Cytological features of stomatal development in the Gramineae. Dev Biol 2: 177-200.

TAIZ, L. and ZEIGER, E. (Ed.) (2006). Plant Physiology. Fourth Edition. Sinauer Associates, Inc.

WEYERS, J.D.B. and MEIDNER, H. (Ed.) (1990). Methods in stomatal research. Longman Scientific and Technical, Harlow.

WRAY, G.A., HAHN, M.W., ABOUHEIF, E., BALHOFF, J.P., PIZER, M., ROCKMAN, M.V. and ROMANO, L.A. (2003). The evolution of transcriptional regulation in eukaryotes. Mol Biol Evol 20: 1377-1419.

WRAY, G.A. (2003). Transcriptional regulation and the evolution of development. Int J Dev Biol 47: 675-684. 


\section{Further Related Reading, published previously in the Int. J. Dev. Biol.}

See our recent Special Issue Placenta edited by Joan S. Hunt and Kent L. Thornburg at: http://www.ijdb.ehu.es/web/contents.php?vol=54\&issue=2-3

\section{Chromatin remodeling in plant development}

José A. Jarillo, Manuel Piñeiro, Pilar Cubas and José M. Martínez-Zapater Int. J. Dev. Biol. (2009) 53: 1581-1596

\section{Evolution and pleiotropy of TRITHORAX function in Arabidopsis}

Zoya Avramova

Int. J. Dev. Biol. (2009) 53: 371-381

Arabidopsis monomeric G-proteins, markers of early and late events in cell differentiation

Mariette Bedhomme, Chantal Mathieu, Amada Pulido, Yves Henry and Catherine Bergounioux

Int. J. Dev. Biol. (2009) 53: 177-185

Epidermal differentiation: trichomes in Arabidopsis as a model system Swen Schellmann and Martin Hülskamp

Int. J. Dev. Biol. (2005) 49: 579-584

Clonal analysis by transposon excision of stomatal clusters in Arabidopsis L Serna and C Fenoll

Int. J. Dev. Biol. (1996) 40: S131-S132

5 yr ISI Impact Factor $(2008)=3.271$
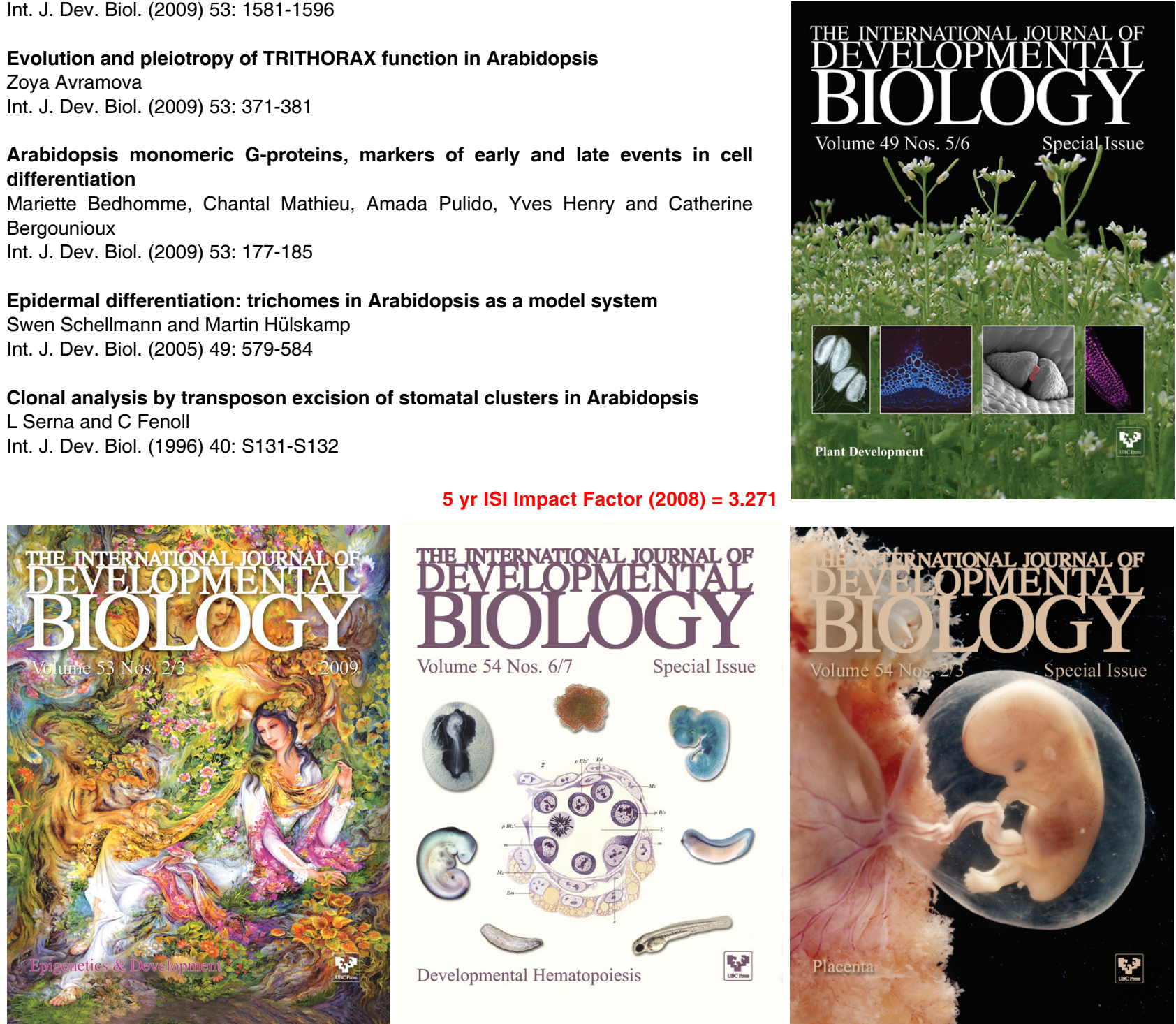

Volume 54 Nos. $6 / 7$

Special Issue
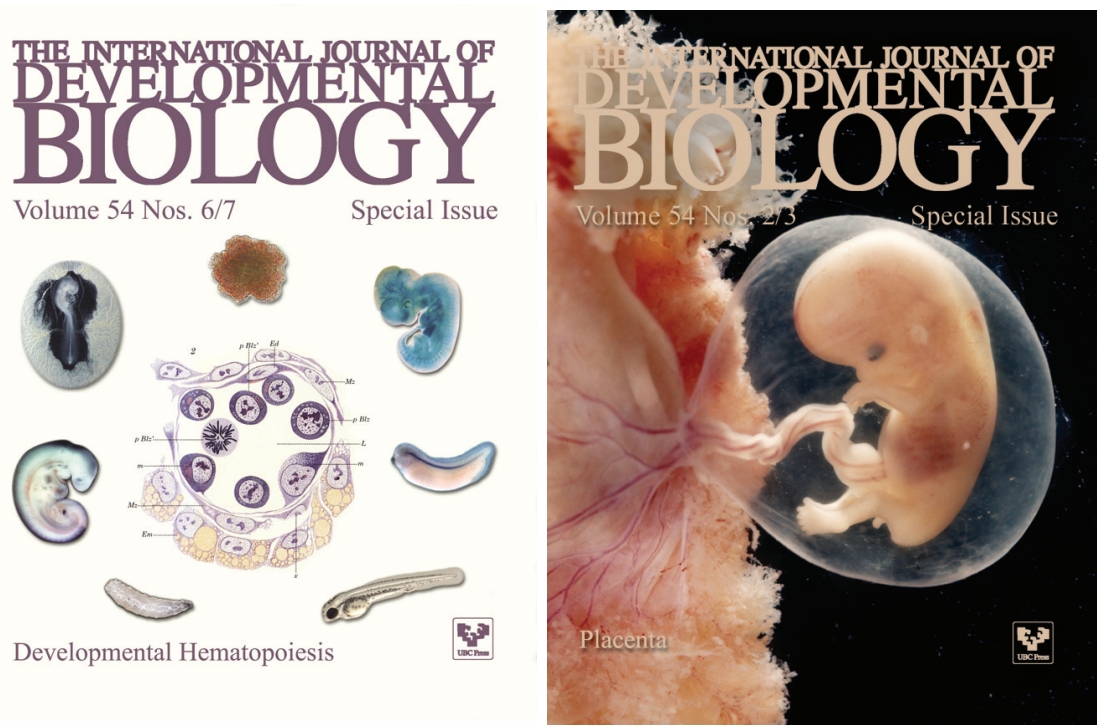